\title{
"Sem tempo, irmão": o trabalho e o tempo livre de entregadores uberizados durante a pandemia de covid-19
}

\section{Out of time: the work and free time of uberized delivery workers during the covid-19 pandemic Sin tiempo: el trabajo y el tiempo libre de los repartidores uberizados durante la pandemia de covid-19}

Bruno Modesto Silvestre ${ }^{a *}$ (D), Samuel Ribeiro dos Santos Neto ${ }^{b}$ (D), Silvia Cristina Franco Amaralc ${ }^{\mathrm{C}}$ (D)

Palavras-chave: Uberização; Pandemia de covid-19; Tempo livre; Lazer.

\section{Keywords:}

Uberization;

Covid-19 pandemic;

Free time;

Leisure.

\section{RESUMO}

O objetivo da pesquisa foi analisar a relação trabalho, tempo livre e lazer dos entregadores que trabalham por meio de plataformas digitais, no contexto da pandemia de coronavírus (Coronavirus Disease 2019 (covid-19)). Trata-se de estudo qualitativo e descritivo, realizado via entrevistas semiestruturadas e questionário on-line, ambos com amostra por conveniência. 0 estudo evidenciou que a precarização dada pelo processo de "uberização" se intensificou no contexto pandêmico. Os resultados apontaram que grande parte do tempo dos entregadores passou a ser dedicado ao trabalho, o que refletiu na redução do tempo livre e na restrição ainda maior do acesso ao lazer.

\begin{abstract}
The objective of the research was to analyze the relationship between work, free time and leisure for delivery personnel who work through digital platforms, in the covid-19 pandemic context. This is a qualitative and descriptive study, carried out via semi-structured interviews and an online questionnaire, both with a convenience sample. The study shows that the precariousness given by the uberization process has intensified in the pandemic context. The results show that a large part of the delivery workers time is now dedicated to work, which reflected in the reduction of free time and in the even greater restriction of access to leisure.
\end{abstract}

\section{RESUMEN}

El objetivo de la investigación fue analizar la relación entre trabajo, tiempo libre y ocio del personal de reparto que trabaja a través de plataformas digitales, en el contexto de la pandemia de covid-19. Se trata de un estudio cualitativo y descriptivo, realizado mediante entrevistas semiestructuradas y un cuestionario online, ambos con muestra de conveniencia. El estudio muestra que la precariedad dada por el proceso de uberización se ha intensificado en el contexto de la pandemia. Los resultados muestran que gran parte del tiempo de los repartidores ahora se dedica al trabajo, lo que se refleja en la reducción del tiempo libre y en la restricción aún mayor del acceso al ocio.

\footnotetext{
aUniversidade de Pernambuco - UPE, Escola Superior de Educação Física. Recife, PE, Brasil.

bUniversidade Estadual de Campinas - Unicamp, Faculdade de Educação. Campinas, SP, Brasil.

'Universidade Estadual de Campinas - Unicamp, Faculdade de Educação Física. Campinas, SP, Brasil.
}

\footnotetext{
*Autor correspondente:

Bruno Modesto Silvestre

E-mail: modesto.b@gmail.com
} 


\section{INTRODUÇÃO}

Desde o início da pandemia de coronavírus (Coronavirus Disease 2019 (covid-19)) no Brasil, persistiu nas cidades brasileiras o som dos escapamentos das motocicletas dos entregadores. Com as típicas mochilas coloridas - as "bags" -, com logomarcas de diferentes plataformas digitais, a entrega de produtos e alimentos via aplicativo ganhou destaque durante o período. Considerado um serviço essencial ${ }^{1}$, esse tipo de trabalho se tornou ainda mais presente na vida de centenas de milhares de pessoas por todo o país. Entretanto, a notoriedade adquirida por essa atividade não se limitou às necessidades do isolamento social; visto que mobilizações ${ }^{2}$ nacionais trouxeram à tona uma série de denúncias relacionadas às precárias condições de trabalho encontradas por quem se cadastra como entregador nas plataformas digitais.

Se, por um lado, o trabalho dos entregadores, em suas motos ou bicicletas, possibilitou que outras pessoas se mantivessem em quarentena, o cenário pandêmico tornou ainda mais evidente o processo de "uberização" do trabalho em curso no Brasil. Segundo pesquisa do Instituto Locomotiva, as plataformas de transporte e entrega de produtos tinham cerca de 5,5 milhões de pessoas cadastradas em 2019 (Gavras, 2019). Por outro lado, em 2020, apesar de não haver dados oficiais fornecidos pelas plataformas, há indícios de que o avanço da crise econômica e social fez esse número se multiplicar. Manzano e Krein (2020), ao analisarem os microdados da Pesquisa Nacional por Amostra de Domicílios Contínua (PNAD Contínua), destacaram que o número de condutores de motocicletas aumentou de 522,1 mil para 729,7 mil (aumento de 39,2\%) entre o primeiro semestre de 2016 e o primeiro semestre de 2020, número que, apesar de não se restringir aos entregadores por aplicativo, abarca o crescimento da modalidade de trabalho nos últimos anos.

O processo de uberização diz respeito a um novo estágio de exploração do trabalho que provoca alterações qualitativas no estatuto do trabalhador e na configuração das empresas, assim como nas formas de organização, gerenciamento, expropriação e controle sobre o trabalho. Trata-se da propagação do modelo just in time, uma forma de trabalho sob demanda que vem se tornando

1 A entrega de produtos de saúde, alimentos, dentre outras, foi considerada uma atividade essencial para o enfrentamento da pandemia de acordo com o Decreto 10.329 (Brasil, 2020).

2 Destacaram-se duas mobilizações nacionais realizadas pelos entregadores: a primeira em 01/07/2020 e a segunda em 25/07/2020. Chamadas de "breque dos apps", reivindicaram aumento do valor recebido por $\mathrm{Km}$; aumento do valor mínimo de entrega; fim do sistema de pontuação e fim dos bloqueios indevidos. tendência nas formas de subcontratação em todo o mundo (Abílio, 2017).

As empresas que medeiam a relação entre os usuários e os trabalhadores cadastrados nas plataformas digitais são o que Abílio (2017) chamou de empresasaplicativo: um modelo de negócio que transfere riscos e custos não mais para outras empresas a elas subordinadas, mas sim para um enorme contingente de trabalhadores autônomos disponíveis ao trabalho. Essas empresas, ao intermediarem a relação entre trabalhadores e usuários, provendo a estrutura digital, estabelecem e administram as regras da prestação de serviço, quem pode ou não permanecer vinculado à plataforma e mesmo a porcentagem do pagamento repassada ao trabalhador.

A emergência das empresas-aplicativo ocorreu com o crescimento da chamada Economia do Compartilhamento ${ }^{3}$, uma nova onda de negócios que se utiliza da Internet para colocar em contato usuários e prestadores de serviços para trocas no mundo físico, como alugueis de curta duração, tarefas domésticas, entregas e viagens de carro (Slee, 2017). O autor argumenta que esse modelo corrobora a propagação de um livre mercado inóspito e desregulado, que coloca em risco áreas da vida que antes eram protegidas. Trata-se de um cenário em que as empresas, por meio de suas plataformas digitais, são as maiores beneficiadas, mas não assumem qualquer responsabilidade ou consequência pela sua lógica de funcionamento.

Em tal modelo, o trabalhador se encontra à disposição para o trabalho, mas só exerce a função quando requisitado, de forma automatizada e controlada. A uberização opera uma mudança sobre o que é ou não trabalho, ou seja, o motorista, o motofretista, o ciclista, podem passar doze horas ou mais conectados e disponíveis, mas são remunerados apenas na exata medida em que exercerem a atividade (Abílio, 2019).

Conforme a realidade sob o capitalismo pandêmico vem servindo como um laboratório para a experimentação e ampliação do trabalho informacional-digital, como o teletrabalho e as demais formas comandadas por algoritmos (Antunes, 2020), a importância de se compreender a relação entre trabalho, tempo livre e lazer dos trabalhadores uberizados reside no fato de tal modalidade figurar, cada vez mais, como um modelo a ser adotado pelos mais diversos setores. Assim, a dinâmica de trabalho dos entregadores via aplicativo fornece indícios substanciais do que os gestores do capital e as grandes corporações pretendem impor em larga escala à classe trabalhadora.

3 Slee (2017) utilizou a expressão Economia do Compartilhamento, mas pontuou que nomenclaturas como consumo colaborativo; economia em rede; economia dos bicos (gig economy), economia da viração, economia de plataforma também representam o mesmo fenômeno. 
Sabendo que a realidade pandêmica exacerbou contradições e acelerou processos de precarização que, mesmo antes do estado de calamidade pública decretado no Brasil em março de 2020, já se mostravam perversos à vida dos trabalhadores, pergunta-se: a pandemia de covid-19 afetou a relação trabalho, tempo livre e lazer dos entregadores que trabalham por meio de plataformas digitais?

As esferas do trabalho, do tempo livre e do lazer guardam estreitas relações. Tais categorias, apesar de distintas, não podem ser compreendidas de forma isolada ou como opostas. Tratam-se de atividades indissociáveis que compõem, cada qual à sua maneira, a totalidade da organização dos tempos sociais. Desse modo, à medida que se compreende que trabalho e lazer formam um binômio (Padilha, 2003), entende-se que as mudanças do mundo do trabalho influenciam as demais dimensões da vida, como o tempo livre, as práticas de divertimento e o lazer.

O objetivo desta pesquisa consistiu, portanto, em investigar a relação trabalho, tempo livre e lazer de entregadores de produtos e alimentos vinculados às plataformas digitais, durante o período de emergência de saúde pública iniciado em março de 2020 no Brasil, que gerou a necessidade do isolamento social em larga escala.

\section{PERCURSO METODOLÓGICO}

Trata-se de uma pesquisa qualitativa, de natureza descritiva. Com o intuito de realizar a triangulação dos dados $^{4}$, foram realizadas entrevistas semiestruturadas e a aplicação de questionários. A pesquisa foi aprovada pelo Comitê de Ética Institucional, sob o registro CEP Unicamp - CAAE 17150619.8.0000.5404.

Foram realizadas oito (8) entrevistas com entregadores, todas à distância (telefone ou videoconferência). 0 questionário ${ }^{5}$ foi aplicado de forma on-line, por meio da plataforma Google Forms, entre os dias 27 de julho e 30 de agosto de 2020, do qual participaram 114 entregadores. A divulgação e distribuição do formulário foi feita sobretudo via grupos de mensagens, com colaboração dos próprios participantes e se embasou na prática de amostragem não probabilística conhecida como "bola de neve". Trata-se de uma técnica de pesquisa utilizada principalmente para fins exploratórios, sendo conveniente para o estudo de populações de difícil acesso e mensuração (Vinuto, 2014).

Nos dois instrumentos, o critério de seleção foi o de conveniência. Portanto, a amostra é não representativa, não probabilística e não aleatória, não havendo pretensões no estudo de universalizar os resultados dentro de um intervalo de confiança preciso. Em se tratando de uma população ainda pouco investigada nos estudos do lazer,

4 A triangulação de dados, de acordo com Flick (2009), diz respeito ao fato de uma questão ser considerada a partir de (pelo menos) dois pontos.

5 As perguntas do questionário foram baseadas na pesquisa "O Lazer do Brasileiro" (Stoppa e Isayama, 2017). visou-se tão somente obter dados preliminares dentro de um escopo temático específico e, a partir disso, dialogar com os campos teóricos do lazer e do trabalho.

$\mathrm{Na}$ transcrição dos excertos das entrevistas, buscou-se preservar os elementos da linguagem oral dos entrevistados. A análise dos dados teve como norte a pergunta de pesquisa e foi feita a partir da interlocução com a bibliografia mobilizada no estudo.

\section{SUJEITOS DA PESQUISA}

Das oito entrevistas, seis foram realizadas com entregadores do gênero masculino e duas com entregadoras do gênero feminino; quatro foram com trabalhadores que residem na capital do Estado de São Paulo (SP) e quatro com entregadores que moram no interior desse mesmo Estado. Todos tinham entre $22 \mathrm{e}$ 34 anos, já estavam cadastrados nas plataformas digitais e obtinham sua principal fonte de renda dessa forma antes do início da pandemia.

Nos questionários foram contabilizadas 114 respostas, das quais 103 foram fornecidas por homens e 11 por mulheres. No que se refere à cor ou raça, 63 se declararam pardos, 22 negros, 28 brancos e 1 participante não declarou cor/raça. Quanto à idade, 44 dos respondentes tinham entre 18 e 25 anos; 51 entre 26 e 35 anos; 16 entre 36 e 45 anos e 3 participantes tinham mais de 46 anos.

Vale pontuar que 88 dos participantes do questionário já trabalhavam como entregadores nas plataformas digitais antes do início da pandemia e 26 iniciaram depois de decretado o estado de calamidade; 98 têm como principal instrumento de trabalho a motocicleta e 16 a bicicleta. A maior taxa de resposta ocorreu na cidade de São Paulo, com 31 entregadores, e as demais estiveram distribuídas entre 16 cidades, em sete Estados (SP, Rio de Janeiro (RJ), Minas Gerais $(\mathrm{MG})$, Paraná (PR), Mato Grosso do Sul (MS), Goiás (GO), Pernambuco (PE)) e Distrito Federal.

Em relação às empresas, a maior parcela dos entregadores ${ }^{6}$ é cadastrada no aplicativo da empresa Ifood, totalizando 102 respondentes. Além dessa empresa, 64 declararam realizar entregas pela plataforma Rappi; 45 pela Uber Eats; 13 pela Loggi; quatro pela empresa Bee e seis são cadastrados também em outras plataformas.

\section{DESEMPREGO, INFORMALIDADE E UBERIZAÇÃO SOB O CAPITALISMO PANDÊMICO: QUANDO TODOS OS TEMPOS SÃO DEDICADOS AO TRABALHO}

A covid-19 tem potencial de atingir todas as pessoas, mas os efeitos são diferentes para as camadas mais ricas e mais pobres da população. Ao passo que a América

${ }^{6}$ Vale destacar que cada entregador geralmente é cadastrado na plataforma de mais de uma empresa. 
Latina e Caribe se tornaram o epicentro mundial da pandemia, 73 bilionários da região, segundo Relatório da Oxfam (2020), aumentaram sua fortuna em U\$ 48,2 bilhões. No Brasil, 42 desses bilionários tiveram sua fortuna aumentada em U\$ 34 bilhões, subindo de US\$123,1 bilhões em março para US\$ 157,1 bilhões em julho de 2020.

Para a classe trabalhadora, sobretudo desempregados e trabalhadores informais, os efeitos deletérios da pandemia foram agudos. No segundo trimestre de 2020 os dados da PNAD Contínua, que abarcam 3 meses desde o início da pandemia, mostram um fechamento de 8,9 milhões de postos de trabalho, com a menor taxa de ocupação da série histórica, iniciada em 2012. A taxa de desocupação no Brasil subiu para 13,3\% (12,8 milhões de pessoas) e o número de desalentados (que deixaram de procurar trabalho, mas estão disponíveis e gostariam de trabalhar) é de 5,7 milhões de pessoas. A população subutilizada, portanto, soma 31,9 milhões (IBGE, 2020).

Os dados da PNAD Contínua também demostram que a taxa de informalidade, que abarca, entre outros, os entregadores cadastrados nas plataformas digitais, atingiu $36,9 \%$ no mesmo período (30,8 milhões de pessoas). Apesar da queda de três pontos percentuais em relação ao trimestre anterior, a diminuição da taxa de informalidade não significa que mais trabalhadores galgaram um vínculo formal, mas sim que muitos informais perderam a sua ocupação no período analisado (IBGE, 2020).

A crise econômica, política e social não está desconectada do sistema de metabolismo antissocial do capital (Antunes, 2020). Mesmo antes da pandemia, dadas as características históricas da formação econômica e social do Brasil, expressiva parcela da classe trabalhadora já se encontrava privada do conjunto de direitos e proteções sociais - característica agravada com a aprovação da Emenda Constitucional 95 e das reformas trabalhista ${ }^{7}$ em 2017 e da previdência em 2019 (Colombi et al., 2020; Manzano e Krein, 2020).

A crise da covid-19 encontrou no Brasil um mercado de trabalho pouco estruturado, heterogêneo, com grande taxa de informalidade, de baixa remuneração e de distribuição desigual dos rendimentos do trabalho (Colombi et al. 2020). De fato, nota-se que nessas circunstâncias uma massa de trabalhadores busca o trabalho por meio do cadastro em plataformas como a Rappi, Ifood, Uber Eats, entre outras. Se já era possível identificar o crescimento dos entregadores cadastrados nos últimos anos (Manzano e Krein, 2020), a pandemia fez o número de "candidatos" crescer exponencialmente. Segundo Mello (2020), o aplicativo IFood, a maior plataforma de entrega de alimentos do país, recebeu, apenas no mês de março de 2020 , o primeiro da

7 Em relação aos efeitos das mudanças na legislação trabalhista sobre as demais dimensões da vida, Silvestre et al. (2020) destacaram que a aprovação dessa contrarreforma fragiliza ainda mais a garantia do direito ao lazer. pandemia no Brasil, 175 mil inscrições, frente às 85 mil em fevereiro do mesmo ano.

Nesse cenário, os relatos sobre as extensas jornadas de trabalho e a baixa remuneração acompanham a crescente necessidade de se buscar "emprego" por meio do cadastro nos aplicativos. Em pesquisa com os entregadores uberizados que utilizam bicicleta como instrumento de trabalho, realizada pela associação Aliança Bike na cidade de São Paulo, foi estimada a média de $40 \mathrm{~km}$ diários percorridos, sendo que $30 \%$ declarou pedalar mais de $50 \mathrm{~km}$ por dia. A média de horas à disposição dos aplicativos ficou em 9 horas e 24 minutos diárias, e $50 \%$ declarou trabalhar até 10 horas por dia. A pesquisa também demonstrou que a remuneração média dos ciclistas era $\mathrm{R} \$ 936,00$ por mês; enquanto o salário mínimo no ano 2019 estava no valor de R\$ 998,00 (Aliança Bike, 2019).

As atividades relacionadas ao trabalho, como indicam os dados da pesquisa "O lazer do brasileiro", são as que mais tomam o tempo das pessoas (Silva et al., 2017). No caso dos entregadores uberizados a realidade não seria diferente. Todavia, tanto nos relatos das entrevistas como nas respostas do questionário, é possível identificar que após o início da pandemia as extensas jornadas de trabalho dos entregadores ficaram ainda mais extenuantes. No questionário, 82 entregadores assinalaram que a quantidade de horas de trabalho aumentou. Quanto à duração da jornada, 69 indicaram trabalhar entre 9 e 12 horas por dia, número já acima das 8 horas diárias de trabalho, e 27 afirmaram trabalhar ainda mais, entre 13 e 16 horas.

Sem jornada estabelecida, é recorrente que esses trabalhadores permaneçam nas ruas até que determinadas metas de remuneração, estabelecidas individualmente, sejam alcançadas, como é possível observar no excerto abaixo:

No início dos apps eu trabalhava umas 7 ou 8 horas por dia, sempre até cumprir minha meta pessoal. Depois de um tempo, eu tive que trabalhar mais horas. Porque o aplicativo é assim: quando ele chega, nossa (!), paga bem pra geral, mas depois, olha.... vai lá pra baixo. [...] Agora na pandemia nem meta eu tenho mais, fico na rua o tempo que dá. O que não dá, é o dinheiro pra pagar as contas. (Entrevistado 4).

O estudo inicial da Rede de Estudos e Monitoramento Interdisciplinar da Reforma Trabalhista (Remir) sobre o trabalho em plataformas digitais durante a pandemia de covid-19, além de identificar o aumento da jornada desses trabalhadores, constatou uma expressiva e generalizada queda na remuneração. A redução no rendimento ${ }^{8}$ ocorreu tanto para os que mantiveram

8 A pesquisa de Abílio et al. (2020) identificou que as medidas de proteção contra o Sars-Cov-2, vírus que causa a covid-19, como máscaras e uso de álcool em gel, são, em geral, custeadas pelos próprios entregadores, o que reduz ainda mais a remuneração. 
como para os que aumentaram o seu tempo de trabalho, e tem relação direta com o aumento no número de entregadores cadastrados nas plataformas durante a pandemia e, também, com a diminuição do valor da hora de trabalho e bonificação, apesar do expressivo crescimento do número de entregas durante o período (Abílio et al., 2020).

É importante destacar que as infindáveis horas de trabalho ocorrem, sobretudo, aos finais de semana, dias de grande procura por entregas de alimentos. Todos os entrevistados e 109 dos 114 respondentes do questionário afirmaram trabalhar aos sábados e/ ou aos domingos. Em geral, o trabalho via aplicativo se caracteriza por tomar conta de grande parte da vida desses trabalhadores, como foi possível observar na reposta de 101 participantes que afirmaram trabalhar entre seis a sete dias por semana.

As extensas jornadas, a baixa remuneração, a necessidade de se estar sempre disponível, conectado ao celular e sujeito aos algoritmos, como forma de se garantir a sobrevivência, evidenciam o que Antunes (2018) caracterizou como escravidão digital. $\mathrm{O}$ autor destacou que a expansão do trabalho digital faz desmoronar a separação entre o tempo de vida no trabalho e o fora dele, gerando uma forma de ocupação que combina o mundo digital e a sujeição aos ideários do mundo corporativo.

À medida que as fronteiras entre o tempo de trabalho e as demais dimensões da vida são borradas, é recorrente que os trabalhadores fiquem pensando em sua ocupação o tempo todo, seja na organização de sua jornada de trabalho ou elaborando estratégias para garantir uma maior remuneração, vide o trecho da entrevista abaixo:

Eu fico ligado no trampo o tempo todo, tá ligado? Troco ideia e fico atento nos grupos dos motoboys sobre a melhor estratégia para conseguir bônus, qual o melhor ponto, região da cidade e hora que tá garantindo melhor retorno no momento... O barato é loco! Se você não estiver ligado nas paradas que tão rolando, cê toma rasteira dos apps e fica pra trás. (Entrevistado 7).

Observa-se, portanto, que esses trabalhadores sentem dificuldade para se desconectar do trabalho. Outro dado que corrobora tal constatação é o fato de 75 dos respondentes terem destacado que não conseguem parar de pensar no trabalho quando desligam os aplicativos em que estão cadastrados.

O trabalho dos entregadores uberizados explicita o processo de flexibilização do tempo de trabalho que ganhou força, segundo Cardoso (2017), desde os anos 1990. Em tal processo, a reaproximação entre o tempo e espaço de trabalho e os de não trabalho, imposta pelo capital, não só impede que o trabalhador continue a não ter poder de decisão sobre o seu tempo de trabalho, mas também limita a capacidade de deliberação sobre o seu tempo de não trabalho. Nota-se, também, uma crescente fragmentação e individuação da atividade laboral e o surgimento de novos tempos dedicados ao trabalho ${ }^{9}$ (Cardoso, 2017).

Em suma, se o trabalho uberizado dos entregadores já demonstrava nítidos traços de precarização, com extensas jornadas, baixa remuneração e ausência de direitos relacionados ao trabalho, a realidade pandêmica, acompanhada da crise social, econômica e política brasileira, aprofundou ainda mais o processo de degradação de suas condições laborais.

\section{SEU TEMPO LIVRE É MEU, ASSINADO: PLATAFORMAS DIGITAIS}

Um dos desdobramentos imediatos da extensa jornada de trabalho dos entregadores uberizados se traduz na expressiva redução do tempo livre ${ }^{10}$. Se, por um lado, essa dimensão da vida já era escanteada pela preponderância do trabalho mesmo antes do estado de calamidade pública causado pela covid-19, a realidade pandêmica reduziu ainda mais o tempo livre dessa categoria de trabalhadores.

Tempo livre? Sem tempo, irmão. A vida aqui é em cima da moto. [...] depois dessa parada aí-o vírus né-, nem me fala, já nem me lembro mais da última vez que passei um dia fora dos corres de entrega. (Entrevistado 3).

O excerto acima, que empresta um de seus trechos como parte do título deste artigo, demarca de forma nítida a prevalência do trabalho em relação ao tempo livre dos entregadores uberizados e a limitação de tempo para as demais dimensões da vida. Igualmente, as respostas do questionário também indicaram a redução do tempo livre durante a pandemia. Dentre as 114 respostas analisadas, 83 entregadores notaram uma redução nessa parcela de tempo, 19 assinalaram que o tempo livre permaneceu o mesmo, 10 não souberam precisar e apenas dois destacaram um aumento em relação a esse tempo.

Para além dessa consequência imediata sobre o tempo livre, a dinâmica de trabalho dos entregadores uberizados também causa uma desorganização sobre as demais dimensões de suas vidas. Não por menos, Cardoso (2017) destacou que os novos tempos de

9 Para além do tempo historicamente considerado como o de trabalho, Cardoso (2017) discutiu a noção de "tempos dedicados" ao trabalho, que compreende as atividades direta ou indiretamente relacionadas ao ato laborativo. Atividades essas que, além de não serem contabilizadas como trabalho e, por consequência, não remuneradas, causam desgastes e desorganizam as demais esferas da vida do trabalhador.

${ }^{10}$ Utiliza-se a expressão tempo livre com a ressalva de que não existe um tempo realmente livre sob realidade imperativa do trabalho estranhado, característica central do metabolismo social do capital (Padilha, 2003). 
Quadro 1. Nível de satisfação com as atividades de lazer.

\begin{tabular}{|c|c|c|c|c|c|c|c|c|c|c|c|}
\hline $\mathbf{0}$ & $\mathbf{1}$ & $\mathbf{2}$ & $\mathbf{3}$ & $\mathbf{4}$ & $\mathbf{5}$ & $\mathbf{6}$ & $\mathbf{7}$ & $\mathbf{8}$ & $\mathbf{9}$ & $\mathbf{1 0}$ & Nível \\
\hline 2 & 1 & 12 & 31 & 25 & 20 & 10 & 7 & 3 & 1 & 2 & $\begin{array}{c}\text { Total } \\
\mathbf{1 1 4}\end{array}$ \\
\hline
\end{tabular}

Fonte: Elaboração própria.

trabalho, facilitados pelas tecnologias da informação e comunicação, se caracterizam pela total assincronia com os outros tempos sociais. Nesse sentido, o lazer, como um fenômeno da vida cotidiana, um tempo e espaço de organização da cultura, permeado por contradições e por disputas de hegemonia (Mascarenhas, 2003), também é impactado pela dinâmica do trabalho uberizado.

Quando indagados sobre a satisfação com as atividades de lazer, em uma escala de zero a dez, na qual o zero significava nenhuma satisfação e o dez a satisfação máxima, os entregadores que responderam o questionário concentraram as respostas abaixo do nível cinco de satisfação, com 91 ocorrências (Quadro 1).

Ao serem cruzadas as respostas do nível de satisfação com as atividades de lazer, com as respostas sobre percepção do tempo livre após o início da pandemia, foi possível notar uma relação entre a diminuição do tempo livre na realidade pandêmica e a insatisfação com as atividades de lazer. Ainda que não se trate de um dado que possa ser generalizado, dadas as dimensões do presente estudo, observou-se que, dentro da amostra investigada, os entregadores que indicaram a diminuição do tempo livre foram, em grande parte, os que também assinalaram níveis de satisfação abaixo de cinco.

Do total, 112 entregadores alegaram que gostariam de vivenciar outras atividades de lazer, no momento não realizadas, em seu tempo livre. Entretanto, a pandemia não foi a principal razão para a não realização dessas atividades. Os dados da questão, com a possibilidade de mais de uma opção ser assinalada, demonstraram que a falta de condições financeiras (84 respostas) e a baixa disponibilidade de tempo (82) estão entre as principais limitações, seguidas do cenário de pandemia (38) e da falta de estrutura adequada (31).

Decerto que no cenário pandêmico os efeitos sobre o trabalho, assim como sua relação com o tempo livre dos entregadores uberizados, influencia a concretude do lazer dessa categoria. De todo modo, Oliveira et al. (2020) apontaram que a pandemia consolida algo que já estava em curso no Brasil: o lazer como um não direito social. Da mesma forma, discutiram que o rebaixamento nas condições de vida da população, consequência da precarização das relações de trabalho e dos ataques às políticas sociais, corrobora a tendência de conversão de todo o tempo de vida do trabalhador em tempo de trabalho (Oliveira et al., 2020).

Importante destacar que as consequências da pandemia sobre o lazer dos entregadores, semelhante ao ocorrido com a esfera do trabalho, mais de que impor uma outra dinâmica, agravou traços já presentes na vida desses trabalhadores. $O$ relato abaixo exemplifica tal cenário:

A gente fica tanto com a cabeça no trabalho, que esquece das outras coisas. Tem uma história que até acho engraçada: eu tinha uma festa de casamento para ir, era na Black Friday. A pessoa vai me casar na Black Friday, mano? (risos). Nesse dia tem bastante entrega pra fazer. $O$ engraçado é que cheguei na igreja uma hora antes do casamento começar. Como eu tinha ido de moto mesmo, não pensei duas vezes, liguei o aplicativo, coloquei o capacete e fui fazer uma corrida, de vestido e maquiada mesmo (risos). No fim, eu cheguei atrasada, mas pelo menos garanti uma entrega (risos). (Entrevistada 1).

Assim, torna-se evidente que o trabalho uberizado, originado a partir da Economia do Compartilhamento, teve a ordem dos pronomes possessivos de seu mito fundador rapidamente invertida: do generoso "o que é meu é seu" 11 para a famigerada lógica do "o que é seu é meu" (Slee, 2017). No caso dos entregadores uberizados, em uma realidade marcada pelo rebaixamento das condições de vida, o que deveria ser a dimensão do tempo livre é tomada, sob a forma de mais trabalho, pelas plataformas digitais.

\section{CONSIDERAÇÕES FINAIS}

Esta pesquisa buscou investigar a relação trabalho, tempo livre e lazer de entregadores cadastrados nas plataformas digitais de entrega de produtos e alimentos, no contexto da pandemia de covid-19. Para tal, foram realizadas entrevistas semiestruturadas, que buscaram apreender em profundidade a dinâmica de vida dentro e fora do trabalho, e aplicados questionários on-line com a mesma categoria de trabalhadores.

A pandemia marcou a ampliação das horas de trabalho dos entregadores que participaram da pesquisa e, por decorrência, uma redução do tempo livre. Da mesma forma, foi observada a insatisfação desses

${ }^{11}$ O título original do livro de Slee (2017), que em português ganhou o nome de "Uberização: a nova onda do trabalho precarizado", é "What's yours is mine: against the sharing economy", justamente um jogo de palavras com a expressão cunhada no início da Economia do Compartilhamento: "What's mine is yours". 
trabalhadores com a dimensão do lazer, reforçando a indissociabilidade entre os tempos sociais.

A investigação traz indícios de que a redução do tempo livre não é uma realidade transitória. Pelo contrário, observa-se um processo em que as transformações em curso no mundo do trabalho, que acarretam a degradação das condições laborais, restringem ainda mais o tempo livre e o acesso ao lazer. Trata-se de uma realidade em que grande parte dos tempos, se não todos, passam a ser dedicados ao trabalho.

Compreender a relação entre trabalho, tempo livre e lazer dos entregadores uberizados denota as tendências e imposições para as condições de vida e o projeto do capital para as relações laborais, sobretudo para os países de capitalismo dependente, como o Brasil. Do mesmo modo, o atual contexto demonstra a necessidade da compreensão das novas realidades do trabalho e os efeitos sobre a vida cotidiana para o campo dos estudos do lazer.

\section{FINANCIAMENTO}

O presente trabalho contou com apoio financeiro na forma de bolsa de doutorado concedida pelo CNPq. Cotas do Programa de Pós-Graduação, número: 140454/2017-9.

\section{CONFLITOS DE INTERESSE} interesse.

Os autores declaram não haver conflitos de

\section{REFERÊNCIAS}

Aliança Bike. Pesquisa de perfil de entregadores ciclistas de aplicativo [Internet]. São Paulo: Aliança Bike; 2019 [citado 2020 Dez 20]. Disponível em: https://aliancabike. org.br/pesquisa-de-perfil-dos-entregadores-ciclistas-deaplicativo/

Antunes R. O privilégio da servidão: o novo proletariado de serviço na era digital. São Paulo: Boitempo; 2018.

Antunes R. Coronavírus: o trabalho sob fogo cruzado. São Paulo: Boitempo; 2020.

Abílio LC. Uberização do trabalho: subsunção real da viração [Internet]. Passa Palavra; 19 fev. 2017 [citado 2020 Dez 20]. Disponível em: http://passapalavra.info/2017/02/110685

Abílio LC. Uberização: do empreendedorismo para o autogerenciamento subordinado. Psicoperspectivas. 2019;18(3):41-51. http://dx.doi.org/10.5027/ psicoperspectivas-vol18-issue3-fulltext-1674.

Abílio LC, Almeida PF, Amorim H, Cardoso ACM, Fonseca VP, Kalil RB, et al. Condições de trabalho de entregadores via plataforma digital durante a COVID-19. Rev Jurid Trab Desenvolv Hum [Internet]. 2020 [citado 2020 Dez 20];3. Disponível em: http://www.revistatdh.org/index.php/ Revista-TDH/article/view/74

Brasil. Decreto no 10.329, de 28 de abril de 2020. Altera o Decreto no 10.282, de 20 de março de 2020, que regulamenta a Lei no 13.979, de 6 de fevereiro de 2020, para definir os serviços públicos e as atividades essenciais. Diário Oficial da União; Brasília; 29 abr. 2020.

Cardoso ACM. Direito e dever à desconexão: disputas pelos tempos de trabalho e não trabalho. Rev. Univ. Fed. Minas Gerais [Internet]. 2017 [citado 2020 Dez 20];23(1-2):6285. Disponível em: https://periodicos.ufmg.br/index.php/ revistadaufmg/article/view/2756

Colombi AP, Campos A, Vallejos Vazquez B, Cadó I, Krein JD, Abílio L, et al. Emprego, trabalho e renda para garantir o direito à vida [Internet]. 2020 [citado 2020 Dez 20]. Disponível em: http://www.cesit.net.br/wp-content/ uploads/2020/04/Versa\%CC\%83o.final_.pdf

Flick U. Qualidade na pesquisa qualitativa. Porto Alegre: Artmed; 2009.

Gavras D. Aplicativos como Uber e iFood são fonte de renda de quase 4 milhões de autônomos. Estadão; 28 abr. 2019 [citado 2020 Dez 20]. Disponível em: https://economia. estadao.com.br/noticias/geral,aplicativos-como-ubere-ifood-sao-fonte-de-renda-de-quase-4-milhoes-deautonomos,70002807079\#: : text=Com\%200\%20 desempenho\%20t\%C3\%ADmido\%20da,plataformas\%20 como\%20fonte\%20de\%20renda

Instituto Brasileiro de Geografia e Estatística - IBGE. Pesquisa Nacional por Amostra de Domicílios Contínua 20 trimestre de 2020 - Divulgação Especial: Medidas de Subutilização da Força de Trabalho no Brasil [Internet]. 28 ago. 2020 [citado 2020 Dez 20]. Disponível em: https://ftp.ibge. gov.br/Trabalho_e_Rendimento/Pesquisa_Nacional_ por_Amostra_de_Domicilios_continua/Trimestral/ Novos_Indicadores_Sobre_a_Forca_de_Trabalho/ pnadc_202002_trimestre_novos_indicadores.pdf

Manzano M, Krein A. A pandemia e o trabalho de motoristas e de entregadores por aplicativo no Brasil [Internet] Cesit/ Unicamp; 13 jul. 2020 [citado 2020 Dez 20]. Disponível em: https://www.cesit.net.br/wp-content/uploads/2020/07/ MANZANO-M-KREIN-A.-2020_A-pandemia-e-os-motoristase-entregadores-por-aplicativo.pdf

Mascarenhas F. Lazer como prática da liberdade. Goiânia: Editora UFG; 2003.

Mello G. Candidatos a entregador do iFood mais que dobram após coronavírus [Internet]. Reuters; 01 abr. 2020 [citado 2020 Dez 20]. Disponível em: https://br.reuters.com/ article/internetNews/idBRKBN21J6N4-OBRIN

Oliveira BA, Custodio ML, Hungaro EM. Disputas em torno do tempo e da vida (ou morte) do trabalhador brasileiro: contribuições para uma análise crítica das relações entre lazer, trabalho e pandemia. Licere. 2020;23(3):216-50. http://dx.doi.org/10.35699/2447-6218.2020.25432.

Oxfam. Quem paga a conta? Taxar a riqueza para enfrentar a crise da covid-19 na América Latina e Caribe [Internet]. Oxfam Internacional; jul. 2020. Nota informativa. [citado 2020 Dez 20]. Disponível em: https://d335luupugsy2. cloudfront.net/cms\%2Ffiles\%2F115321\%2F15997803591 595622094Nota_informativa_da_Oxfam_Quem_Paga_a_ Conta.pdf

Padilha V. Se o trabalho é doença, o lazer é remédio? In: Müller A, Costa LP, editores. Lazer e trabalho: um único 
ou múltiplos olhares. Santa Cruz do Sul: Edunisc; 2003. p. 243-66.

Silva LF, Moreno JCA, Veraldo KC. Relações com o trabalho. In: Stoppa EA, Isayama HF, editores. O lazer no Brasil: representações e concretizações das vivências cotidianas. Campinas: Autores Associados; 2017.

Stoppa EA, Isayama HF. O lazer no Brasil: representações e concretizações das vivências cotidianas. Campinas: Autores Associados; 2017.
Silvestre BM, Miguel RS, Assis AESQ. Reforma trabalhista e o (não) direito ao lazer. Licere. 2020;23(1):419-38. http:// dx.doi.org/10.35699/1981-3171.2020.19780.

Slee T. Uberização: a nova onda do trabalho precarizado. São Paulo: Elefante; 2017.

Vinuto J. A amostragem em bola de neve na pesquisa qualitativa: um debate em aberto. Tematicas. 2014;22(44):203-20. http://dx.doi.org/10.20396/tematicas.v22i44.10977. 